\title{
ARTIKELEN
}

\section{Discriminatie van IS en Al-Nusra-strijders bij intrekking Nederlanderschap in Unierechtelijk perspectief}

\author{
Florimond Wassenaar
}

'Discriminatie!' is een van de meest gehoorde beweringen over onrecht binnen en buiten de rechtszaal. Maar het is tegelijk een argument dat door de rechter het minst vaak gehonoreerd wordt. Vaak gebruiken mensen de term om aan te duiden dat ze zich onterecht behandeld voelen of menen onrecht te zijn aangedaan. Het is niet voor niets dat men in de common law-landen het principe van 'discriminatie' nog altijd als het belangrijkste juridisch gereedschap kent. Er wordt gekeken naar gelijke gevallen in de jurisprudentie en als het rechtsgevoel wil dat het in een nieuwe zaak toch anders gaat dan is daar 'the beautiful art of distinguishing'. Op dat moment zijn de professionele juristen al in het geding betrokken en die weten het al snel te maken tot een sofistisch schaakspel waarbij de burger moet toegeven geen grootmeester te zijn.

Soms is er een enkel geval waarin 'prima facie' duidelijk is dat er iets niet klopt. Zo is het ook met artikel 14 lid 4 van de Rijkswet op het Nederlanderschap (RWN). ${ }^{1}$ Dat artikel komt erop neer dat alleen iemand die een dubbele nationaliteit heeft zijn Nederlanderschap kan verliezen in verband met terroristische activiteiten in het buitenland. De term tweederangs-Nederlanders valt al snel en het is die snelheid die vragen oproept. Of dit onderscheid tussen monopatriden en bipatriden voldoende is om te spreken van discriminatie zal hieronder worden uitgewerkt.

Ik zal mij beperken tot een Unierechtelijke beschouwing van het mogelijk discriminatoire karakter van deze bepaling. ${ }^{2}$ Ik zal dat doen aan de hand van het recente arrest-Chez ${ }^{3}$ van 16 juli 2015 van het Hof van Justitie van de Europese Unie (Hof van Justitie). In de andere hand zal ik het oude arrest-Michelletti, ${ }^{4}$ dat het licht zag op 7 juli 1992, meevoeren in mijn betoog. Ten slotte zal ik aan de

1 Artikel 14 lid 4 RWN luidt: 'Onze Minister kan in het belang van de nationale veiligheid het Nederlanderschap intrekken van een persoon die de leeftijd van zestien jaar heeft bereikt en die zich buiten het Koninkrijk bevindt, indien uit zijn gedragingen blijkt dat hij zich heeft aangesloten bij een organisatie die door Onze Minister, in overeenstemming met het gevoelen van de Rijksministerraad, is geplaatst op een lijst van organisaties die deelnemen aan een nationaal of internationaal gewapend conflict en een bedreiging vormen voor de nationale veiligheid.'

2 Voor een uitgebreide analyse van de artikelen 8 en 14 EVRM (discriminatieverbod) zie R. de Leeuw, Intrekken van het Nederlanderschap van uitgereisde jihadisten. Toetsing aan internationale mensenrechten: recht op een nationaliteit, discriminatieverboden en rechtsbescherming, Weert: Celsus Juridische uitgeverij 2016.

3 HvJEU, C-83/14, 16 juli 2015 (Chez Razpredelenie Bulgaria), JV 2015/308 m.nt. P.R. Rodrigues, ECLI:EU:C:2015:480.

$4 \quad$ HvJEG, C-369/90, 7 juli 1992 (Micheletti), RV 1992, 93. 
hand van het arrest-Rottmann ${ }^{5}$ laten zien dat staatloosheid een optie is voor de hoogste Unierechter, want dat laatste is de spil waar het in deze hele aangelegenheid om draait. Staatloosheid en het verdrag daartegen is wat de wetgever ervan heeft weerhouden om artikel 14 lid 4 RWN niet van toepassing te verklaren op alle Nederlandse strijders die in Syrië of Irak voor IS of Al-Nusra vechten, want alleen voor bipatride Nederlanders is deze tijdelijke bepaling in de RWN geschreven.

\section{Directe discriminatie}

Allereerst is het nodig om vast te stellen of er een Unierechtelijk belang in het geding is dat de discriminatierichtlijn 2000/43/EG van toepassing laat zijn. De richtlijn 2000/43/EG heeft als doel een kader te creëren voor bestrijding van discriminatie op grond van ras of etnische afstamming. In artikel 2 lid 2, waarin het begrip discriminatie nader wordt uitgelegd, is bepaald dat de richtlijn niet van toepassing is op verschillen in behandeling gebaseerd op nationaliteit en geen afbreuk doet aan voorwaarden voor toegang en verblijf voor onderdanen van derde landen en staatlozen. Het is dus de vraag of discriminatie op grond van een dubbele nationaliteit onder de definitiebepaling valt van de richtlijn.

In dit verband is allereerst instructief de zaak Jyske Finans a/s Ligebehandlingsnævnet (C-668-15) waarin het Hof van Justitie oordeelde dat er geen sprake was van discriminatie vanwege een andere etniciteit of allochtone afkomst vanwege het onderscheid dat werd gemaakt tussen Deense onderdanen die in Denemarken of de Unie waren geboren en Denen die in een ander, niet-Unieland waren geboren. ${ }^{6}$ In rechtsoverwegingen 24 en 25 van dit arrest wordt los van nationaliteit geoordeeld dat een geboorteplaats buiten de Unie niet impliceert dat er sprake is van een andere etnische afstamming.

Etnische afstamming wordt volgens het arrest-Chez bepaald door de gedachte dat maatschappelijke groepen worden gekenmerkt door met name een gemeenschappelijke nationaliteit, religie, taal, culturele en traditionele achtergrond en gemeenschappelijke levensomstandigheden. ${ }^{7}$ In het arrest-Chez wordt dit het geval geacht te zijn voor de Roma in Bulgarije. De discriminerende maatregelen tegen de Roma waren gericht op wijken waar aantoonbaar de meerderheid van Romaachtergrond was. Een dergelijke gemeenschappelijke religieuze, culturele of traditionele achtergrond zal dus ook moeten worden bewezen voor de meerderheid van de bipatriden in Nederland wil de richtlijn van toepassing zijn. De cijfers lijken daar geen steun voor te bieden omdat er vele bipatriden zijn van verschil-

5 HvJEU (Grote kamer), C-135/08, 2 maart 2010 (Rottmann), JV 2010/122.

6 Denen die buiten de Unie waren geboren, moesten voor de aanvraag voor een lening bij een kredietinstelling voor de aankoop van een auto aanvullend een identiteitsbewijs overleggen in de vorm van een kopie van hun paspoort of verblijfsvergunning. Het ging in die casus om een Deen van Bosnische afkomst die zich erover beklaagde dat nu zijn geboorteplaats buiten de Unie was gelegen hij zijn paspoort of verblijfsvergunning moest overleggen. Gelet hierop meende hij dat hij gediscrimineerd werd omdat Denen die in een land van de Unie geboren waren dat niet hoefden. 
lende etnische achtergronden. Wel blijkt uit cijfers uit 2012 van het Centraal Bureau voor de Statistiek dat Turkse en Marokkaanse Nederlanders het leeuwendeel van de bipatriden in Nederland vormen. ${ }^{8}$ Ten aanzien van deze groep kan worden gesteld dat ze eenzelfde religieuze achtergrond heeft en dat de meeste leden van die groep ouders of grootouders hebben die als gastarbeider naar Nederland gekomen zijn. Of deze in meerderheid gedeelde kenmerken van bipatriden voldoende zullen zijn om ze onder de definitie van etnische groep te scharen om zo een succesvol beroep op de richtlijn te kunnen doen, zal moeten blijken. ${ }^{9}$

Ten slotte wordt nog gewezen op artikel 21 van het Handvest waarin een ruimere bepaling is opgenomen betreffende gelijke behandeling. Die bepaling houdt ook een verbod in op ongelijke behandeling op basis van nationaliteit. Voor zover een beroep op de richtlijn niet zou slagen, kan wel een Unierechtelijke discriminatietoets worden aangelegd aan de hand van artikel 21 Handvest. Het ligt dan voor de hand dat de bevindingen uit het arrest-Chez bij zo'n beoordeling reflexwerking zullen hebben.

De vraag of er sprake is van directe discriminatie op grond van nationaliteit zou, vertaald naar de bepaling van artikel 2 lid 1 sub a van de richtlijn, als volgt moeten worden geformuleerd. Er is sprake van directe discriminatie op grond van nationaliteit wanneer iemand op grond van nationaliteit ongunstiger wordt behandeld dan een ander in een vergelijkbare situatie is of zou worden behandeld. Dat iemand met een andere (niet Unierechtelijke) nationaliteit anders kan en mag worden behandeld, is uitdrukkelijk in de richtlijn opgenomen. Immers, anders is het voeren van vreemdelingenbeleid een stuk problematischer. Wat in dit verband van belang is, is dat de bipatride Nederlanders anders worden behandeld dan hun landgenoten die alleen de Nederlandse nationaliteit hebben, juist op grond van die vreemde nationaliteit. Dat is in dit perspectief problematisch omdat de vreemde nationaliteit geen kenmerk is van die Nederlanders op basis waarvan jegens hen of hun familieleden vreemdelingenbeleid kan worden gevoerd. Immers, zij hebben toelating op grond van hun Nederlanderschap. De uitzondering zoals geformuleerd in de richtlijn is in dit geval dan ook niet van toepassing.

Verder moet in dit verband worden bedacht dat de legitimatie van deze maatregel en wel de bescherming van de nationale veiligheid merkwaardig aandoet. Immers, Nederlanders met één nationaliteit die zich hebben aangesloten bij de groeperingen als IS en Al-Nusra vormen ook, zo mag worden aangenomen, een gevaar voor de nationale veiligheid. Of moet uit de wetsgeschiedenis worden afgeleid dat bipatriden gevaarlijker zijn dan Nederlanders zonder een tweede nationaliteit? De

8 https://www.cbs.nl/nl-nl/nieuws/2012/12/1-2-miljoen-nederlanders-met-dubbele-nationaliteit.

9 Vergelijk in dit verband het wetgevingsadvies over artikel 14 lid 4 RWN van het College voor de Rechten van de Mens van 17 juni 2016, kenmerk 2016/0096/AvD/JB/LR p.3: 'Het College wijst in zijn adviezen op het potentieel stigmatiserende effect van de voorgenomen maatregelen ten aanzien van moslims en andere personen met een migratieachtergrond. Dit kan leiden tot verdere polarisatie in de samenleving. Risico hiervan is een zich opbouwend wantrouwen bij personen met een migratieachtergrond of met een islamitische geloofsovertuiging tegen de rest van de samenleving. Iets wat radicalisering juist in de hand kan werken.' 
vraag stellen is hem beantwoorden lijkt het, en er wordt in de wetsgeschiedenis ook geen enkel woord aan vuil gemaakt.

De aangevoerde legitimatie voor het onderscheid tussen de verschillende groepen Nederlanders is dat het Verdrag tot beperking der staatloosheid ${ }^{10}$ (staatlozenverdrag) ontneming van de Nederlandse nationaliteit verbiedt als zij staatloosheid tot gevolg zou hebben. ${ }^{11}$ Op zichzelf is dat juist, maar het is de vraag of de aard van het verbod voortvloeiend uit het staatlozenverdrag als legitimatie kan dienen voor het onderscheid dat 14 lid 4 RWN maakt tussen monopatride en bipatride Nederlanders. Het staatlozenverdrag staat namelijk uitdrukkelijk staatloosheid toe in geval van handelen in strijd met de belangen van de lidstaat waaronder dus ook terroristisch handelen dat leidt tot gevaar voor de nationale veiligheid. ${ }^{12}$ Volgens het staatlozenverdrag kan monopatride Nederlanders dus wel degelijk hun Nederlanderschap worden afgenomen en is de redenering in de memorie van toelichting bij 14 lid 4 RWN dat het staatlozenverdrag ontneming van het Nederlanderschap van monopatriden verbiedt niet gebaseerd op een correcte uitleg van de grondslagen van het verdrag. De reden waarom het staatlozenverdrag de lidstaat Nederland verbiedt om zijn monopatride onderdanen het Nederlanderschap af te nemen is een technische, en wel dat de verliesbepaling niet al voor de inwerkingtreding van het verdrag in de nationaliteitswetgeving van ons land was opgenomen en er evenmin een voorbehoud is gemaakt, destijds in 1964.

Dat in de memorie van toelichting het staatlozenverdrag van stal wordt gehaald ter rechtvaardiging van het onderscheid tussen monopatride en bipatride Nederlanders is dubieus. Immers, er is geen dogmatisch beletsel gelegen in het staatlozenverdrag om artikel 14 lid 4 RWN niet ook van toepassing te laten zijn op monopatriden. Bij voortschrijdend inzicht of gewijzigde politieke ontwikkeling is in zo'n geval de aangewezen weg om bij de verdragsluitende partijen aan te dringen op verdragswijziging. Het geeft in het licht van het staatlozenverdrag in ieder geval geen pas om nu juist het verdrag als legitimatie voor het onderscheid aan te bieden terwijl het in feite gaat om een materieel verdragsrechtelijke mogelijkheid die de lidstaat Nederland destijds willens en wetens heeft laten schieten. ${ }^{13}$

10 Verdrag tot beperking der staatloosheid, New York, 30-08-1961, Trb 1967, 124.

11 Nota van toelichting, Kamerstukken II 2015/16, 34356 (R2064), nr. 3, p. 15: ‘[...] er (is) hierbij evenwel sprake van een gerechtvaardigd onderscheid. De bescherming van staatloosheid is immers de grond om in het ene geval niet en in het andere geval wel tot intrekking van de nationaliteit wordt overgegaan. Dit onderscheid wordt reeds in de bestaande rijkswet gemaakt bij intrekkingen op grond van artikel 14, tweede lid.'

12 Artikel 3 staatlozenverdrag voor zover van belang luidt : 'Ongeacht het bepaalde in het eerste lid van dit artikel behoudt een Verdragsluitende Staat het recht iemand zijn nationaliteit te ontnemen, indien die Staat ten tijde van de ondertekening of de bekrachtiging van of de toetreding tot dit Verdrag een daartoe strekkende verklaring aflegt onder opgave van de gronden, welke zijn nationale recht voor die ontneming kent en waarvoor de beweegreden is geweest: a) dat betrokkene, op een wijze die onverenigbaar is met zijn plicht tot trouw aan de Verdragsluitende Staat, (i)... (ii) zich dusdanig heeft gedragen, dat daardoor aan de wezenlijke belangen van de Staat ernstig afbreuk wordt gedaan.'

13 De Groot, in: M.S. Berger (red.), Nederlanders in de heilige oorlog: zoeaven, brigadisten en jihadisten, Den Haag: Boom Juridische uitgevers 2015, p. 114. 
Het staatlozenverdrag wordt zo ingezet voor een doel waar het niet voor geschreven is. Immers, het verdrag is opgesteld om mensen te vrijwaren van staatloosheid. De overheid gebruikt het staatlozenverdrag dat bedoeld is ter bescherming van burgers tegen willekeur van overheden nu juist tegen bipatride jihadisten om hen zo uit Nederland te kunnen weren en in feite en ook de jure jegens hen willekeur te betrachten. Dat is de wereld op zijn kop.

Het feit dat er inderdaad al eerder intrekkingsbevoegdheden in de RWN zijn opgenomen bij onherroepelijke veroordelingen waarbij onderscheid bestaat tussen Nederlanders die wel of niet bipatride zijn, ${ }^{14}$ maakt evenmin dat het hier gaat om een gerechtvaardigd onderscheid. Fouten uit het verleden bieden uiteraard geen legitimatie voor dezelfde onrechtmatigheden in de toekomst. Ook deze bevoegdheden zijn op dezelfde manier in strijd met het Unierechtelijke non-discriminatiebeginsel zoals in dit artikel wordt gesteld.

Omdat directe discriminatie die valt onder het toepassingsbereik van de richtlijn 2000/43/EG niet is toegestaan, is reeds duidelijk dat de toepassing van de gewraakte maatregel van het intrekken van de Nederlandse nationaliteit van betrokkenen in strijd is met artikel 2 lid 1 van de richtlijn of in ieder geval met het Unierechtelijke discriminatieverbod van artikel 21 Handvest. In dat laatste geval zal er dan wel sprake moeten zijn van een analoge toepassing van de richtlijn. Als dat niet het geval is, kan betoogd worden met een beroep op artikel 21 Handvest dat er sprake is van indirecte discriminatie.

\section{Indirecte discriminatie}

Er is sprake van indirecte discriminatie wanneer een ogenschijnlijk neutrale bepaling, maatstaf of handelwijze personen van een bepaald ras of een etnische afstamming in vergelijking met andere personen bijzonder benadeelt, tenzij deze bepaling of handelwijze objectief wordt gerechtvaardigd door een legitiem doel en de middelen voor het bereiken van dat doel passend en noodzakelijk zijn. Ten aanzien van indirecte discriminatie hoeft niet vast te staan dat ze intentioneel is zijdens de regelgever. Het gaat aldus om het effect van een bepaalde maatregel ten aanzien van een bepaalde etnische groep. ${ }^{15}$ Het lijkt wel duidelijk dat de maatregel van het intrekken van de Nederlandse nationaliteit effectief leidt tot ongelijke behandeling van Nederlanders met een niet-westerse tweede nationaliteit. Wellicht zal ook vanwege het ruimere discriminatieverbod van artikel 21 Handvest een beroep op reflexwerking van de richtlijn nodig zijn om zo een vergelijkbare toetsing te verkrijgen overeenkomstig het arrest-Chez.

Het lijkt duidelijk dat bipatride Nederlanders die in het strijdgebied in Syrië opereren onder de vlag van IS en Al-Nusra, bijzonder worden benadeeld bij intrekking van hun Nederlanderschap ten opzichte van hun strijdmakkers die alleen de Nederlandse nationaliteit hebben. Vervolgens zal dan moeten worden gekeken of er niettemin sprake is van een legitiem doel. Uit het reeds aangehaalde arrest- 
Chez blijkt dat aan het vereiste van een legitiem doel twee elementen verbonden zijn. Ten eerste gaat het om het beschermen van een rechtsgoed als zodanig en ten tweede om de vraag in welke mate de getroffen maatregel geacht kan worden een oplossing te zijn voor het bereiken van dat doel. Het voorkomen van aanslagen en het beschermen van de nationale veiligheid is zonder meer een legitiem doel. Echter, ten aanzien van de tweede vraag zijn er twijfels over de legitimiteit van het doel. Immers, de maatregel van het ontnemen van de Nederlandse nationaliteit van betrokkenen veronderstelt dat zij een gevaar vormen voor de nationale veiligheid omdat zij lid zijn van een terroristische groepering.

$\mathrm{Nu}$ kan uiteraard niet worden ontkend dat de Al-Nusra- en IS-groeperingen meerdere malen te kennen hebben gegeven ook doelen te zoeken in de Westerse wereld, waaronder Nederland. De vraag is evenwel of de doelstelling van een terroristische organisatie en zelfs een lidmaatschap, voor zover dat gelet op de invoeringsdatum van 14 lid 4 RWN per 2 maart 2017 kan worden bewezen, tevens inhoudt dat daarmee de betrokken persoon een gevaar vormt voor de nationale veiligheid.

Er wordt veelvuldig ook in de wetsgeschiedenis aangehaald dat er uitreizigers zijn die zich inderdaad schuldig hebben gemaakt aan aanslagen bij terugkomst in het land van herkomst. Echter, daarbij is buiten beeld gebleven dat er ook vele terugkeerders zijn die nadat zij hun rechtvaardige straf hebben gekregen, zijn gereclasseerd en aldus geen gevaar meer vormen voor de nationale veiligheid.

Ten slotte is er nimmer een correlatie aangetoond tussen uitreis en nationale veiligheid bij terugkeer van de uitreiziger. In dit verband wordt gewezen op een artikel in het NJCM van Staring, De Wit en Nummerdor. ${ }^{16} \mathrm{Zij}$ stellen dat er geen onderzoek is gedaan naar het verband tussen een persoon die naar Syrië is gegaan en de eerdergenoemde gevaarzetting. ${ }^{17}$ Factoren die van belang zijn bij een dergelijke gevaarzetting zijn tot op heden slechts algemeen van aard. Het is dus zeer de vraag of het ontnemen van de Nederlandse nationaliteit wel een adequate oplossing biedt voor het probleem.

In dit verband wordt nog verwezen naar het arrest-Chez waarin onder rechtsoverweging 116 uitdrukkelijk wordt geformuleerd dat fenomenen waarvan gesteld wordt, zonder adequaat bewijs, dat die zich zouden voordoen met betrekking tot de betreffende groep, niet voldoende zijn om een legitiem doel aan te nemen. In dit verband wordt gedoeld op de algemene dreigingsanalyses die afkomstig zijn van de Nationaal Coördinator Terrorisme en Veiligheid en de Algemene Inlichtin-

16 R.H.J.M. Staring, J.C. de Wit en H. Nummerdor, 'De brede aanpak van radicalisering: effecten en effectiviteit. Enkele juridische en criminologische kanttekeningen bij het weigeren van een paspoort aan vermeende Syriëgangers', NJCM 2014, jaargang $39 \mathrm{nr} .6$, p. 690-710.

17 De geschetste incidenten in Nederland en andere Europese landen met (teruggekeerde) Syriëgangers kunnen weliswaar zeer ernstig zijn, maar het aantal blijft tot op heden gering. In een interview met NRC Handelsblad stelt het Hoofd Veiligheid van de gemeente Delft - een van de geoormerkte 'risicosteden' - die verantwoordelijk is voor onder meer de lokale aanpak van radicalisering en jihadgangers dat het probleem dan ook niet moet worden overdreven. Op de constatering dat er in 2013 dertien dodelijke slachtoffers ten gevolge van terrorisme in Europa zijn gevallen, reageert de ambtenaar met: 'Er vallen meer doden door fijnstof (...). Dat zeg ik niet om de problemen te bagatelliseren, maar wel om ze in perspectief te plaatsen.' Zie B. Blokker en C. Pelgrim, 'De imam tegenspreken - dat kan een teken zijn', in: NRC Handelsblad, 18 april 2014. 
gen- en Veiligheidsdienst. Hoewel deze analyses ongetwijfeld belangwekkend zijn en uiteraard zorgen teweegbrengen jegens personen die zich onder de vlag van IS of Al-Nusra in het strijdgebied ophouden, kan deze zorg niet als grondslag dienen omdat het gaat om algemeenheden die, zoals Staring, De Wit en Nummerdor hebben aangetoond, niet beslissend zijn voor de beoordeling van daadwerkelijke gevaarzetting voor de nationale veiligheid in een individueel geval.

Als kan worden aangenomen dat er sprake is van een legitiem doel, hetgeen los van de individuele casus, in algemene zin als het gaat om de nationale veiligheid aannemelijk is, dan zal moeten worden gekeken of er sprake is van het toepassen van een middel dat voor het bereiken van dat doel passend en noodzakelijk is. Uiteraard is het zo dat bij ongecontroleerde binnenkomst in Nederland van een staatsgevaarlijk persoon er een kans bestaat dat het gevaar dat van die persoon uitgaat zich verwezenlijkt. Het is echter de vraag of het afnemen van de Nederlandse nationaliteit dat kan voorkomen. Immers, het bezit of houderschap van een Nederlands paspoort kan ook door de vervallenverklaring op grond van artikel 23 Paspoortwet van dit paspoort en signalering daarvan via internationale opsporingsorganisaties afdoende worden gezekerd. De ontneming van de Nederlandse nationaliteit biedt te dien aanzien als het gaat om de controle en de beveiliging van de grenzen geen aanvullende bescherming. Het voordeel dat betrokkenen aan de Nederlandse nationaliteit zouden kunnen ontlenen, is in geval van arrestatie in het buitenland dat zij kunnen worden overgeleverd of uitgeleverd. Dan is er evenwel sprake van gecontroleerde binnenkomst. Door het afnemen van het Nederlanderschap is die gecontroleerde repatriëring niet meer mogelijk en kan zelfs betoogd worden dat de maatregel zelfs contrair is aan het belang voor de nationale veiligheid.

Al met al lijkt er geen sprake te zijn van een noodzakelijk middel nu er ook nog andere mogelijkheden zijn om de nationale veiligheid te doen beschermen. Het is onduidelijk voor welk probleem het ontnemen van de Nederlandse nationaliteit in dit soort zaken de oplossing is. Er is mitsdien geen legitimatie voor indirecte discriminatie nu er grote vraagtekens moeten worden geplaatst bij de passendheid en noodzakelijkheid van het onderscheid jegens bipatride Nederlanders.

\section{Micheletti en Rottmann}

Ten slotte dient bij ontneming van een Unienationaliteit een Unierechtelijke evenredigheidsbeoordeling te worden gemaakt. Over de verplichte toepasselijkheid van die evenredigheidsbeoordeling zoals gestipuleerd door het Hof van Justitie in het arrest-Rottmann ${ }^{18}$ bestaat in de nationale rechtspraak inmiddels geen onduidelijkheid meer. ${ }^{19} \mathrm{Om}$ iets te kunnen zeggen over welke elementen in die evenredigheidsbeoordeling zullen moeten worden betrokken bij het ontnemen van de Unienationaliteit van bipatride Unieburgers, is het zaak om aandacht te besteden aan het arrest-Micheletti vs. Spanje. ${ }^{20}$ In het arrest-Micheletti werd 
ongelijke behandeling ten aanzien van het Unierecht (vrij verkeer) vanwege het bezit van een tweede nationaliteit van een derde land als onrechtmatig gekenschetst. Hoewel de casus van Micheletti een andere was, lijken er wel degelijk overeenkomsten te zijn met de omstandigheden die in de betrokken gevallen een rol spelen.

In de zaak Micheletti werd de Italiaan Micheletti vestiging als tandarts in Spanje onthouden omdat het land waar hij had verbleven voordat hij naar Spanje kwam, een derde land was (Argentinië) en hij daarvan tevens de nationaliteit bezat. Zou hij alleen Italiaan geweest zijn, dan had hem de inschrijving als tandarts destijds in Spanje niet kunnen worden onthouden. Het Hof van Justitie oordeelde dat deze regeling in strijd was met het Unierecht, omdat de Italiaanse nationaliteit van Micheletti doorslaggevend was en de voormalige woonplaats en andere nietUnienationaliteit van belanghebbende Micheletti daar niets aan afdeed.

In zaken waarbij er sprake is van intrekking van het Nederlanderschap op grond van artikel 14 lid 4 RWN ontstaat deze bevoegdheid vanwege de bijkomende, in het licht van de rechten die verbonden zijn met het Unieburgerschap, arbitraire omstandigheid dat de Unieburger ook nog de nationaliteit heeft van een ander land. Immers een Nederlandse jihadist zonder een tweede nationaliteit kan zich, uiteraard na het voldoen aan de Nederlandse justitie, elders in Europa maar ook in Nederland op grond van dat Nederlanderschap vestigen om binnen de EU economische activiteiten te gaan verrichten. Dit recht is hem of haar gegeven op grond van artikel 20 en artikel 21 van het Werkingsverdrag van de Unie (VWEU). Echter, dit recht gaat die bipatride Nederlander worden onthouden, nu deze Unie-onderdaan een tweede nationaliteit heeft. Deze andere nationaliteit is in het licht van het Nederlanderschap/Unieburgerschap en de rechten die daaraan worden ontleend irrelevant, zo leert het arrest-Micheletti als het gaat om het uitoefenen van Unierechtelijke aanspraken en rechten.

Een besluit op basis van artikel 14 lid 4 RWN dat de uitoefening van deze (toekomstige) rechten onmogelijk maakt, is wellicht in strijd met het Unierecht. Het gaat hier om een vorm van ongelijke behandeling van burgers van de Unie, die zich niet verdraagt met de inhoud van het Unieburgerschap zoals vormgegeven onder andere in artikel 21 van het Handvest.

Het verschil in zoverre met de tandarts Micheletti is dat Nederlandse IS- en AlNusra-strijders in Syrië geen gebruik (lijken te) maken van hun rechten op grond van het vrij verkeer van personen en goederen zoals Micheletti evident wel deed toen hij zich als Italiaan in Spanje wilde gaan vestigen als tandarts. Echter, een eventuele verstekveroordeling of aanstaande vervolging houdt ook in dat er een reclasseringsbelang is en er aldus wel degelijk beroep zal worden gedaan op sociale voorzieningen. Deze vallen wel degelijk binnen de reikwijdte van het Unierecht. Ten slotte wordt er ook nog op gewezen dat een potentiële aanspraak in de toekomst op de rechten zoals gegeven in de artikelen 20 en 21 VWEU wel degelijk ook relevant kan zijn en aldus het Unierecht in die zin kan activeren zoals het Hof 
van Justitie in de zaak Michelletti aannam. In dit verband wordt verwezen naar de beoordeling in de zaak Ruiz Zambrano. ${ }^{21}$

Het bepaalde in artikel 14 lid 4 RWN miskent het leidende beginsel van het arrest-Micheletti en wel dat de Unienationaliteit de primaire nationaliteit is. In het licht van het Unierecht moet de lidstaat in feite blind zijn voor die andere nationaliteit en geeft het geen pas om die tweede nationaliteit als joker in te zetten om Unieburgers omwille van nationale veiligheidsaspecten die niets met het Unieburgerschap zelf van doen hebben, hun Unierechten te ontnemen.

De tweede beoordeling die in het kader van de Unierechtelijk gevormde jurisprudentie met betrekking tot het afnemen van het Unieburgerschap moet worden betracht, maakt dat duidelijk. Het gaat dan om het arrest-Rottmann. In dit verband moet worden bedacht dat het arrest-Rottmann is gewezen naar aanleiding van een door de Unieburger bij het verwerven van de Unienationaliteit gepleegd bedrog. In rechtsoverweging 51 van dat arrest wordt overwogen dat het Unieburgerschap een uitdrukking is van wederzijdse loyaliteit tussen enerzijds de lidstaat en anderzijds de burger die zich laat naturaliseren tot de nationaliteit van die lidstaat. In het arrest-Rottmann wordt in ieder geval impliciet geaccepteerd dat (overigens wel na een evenredigheidsbeoordeling) een en ander tot gevolg kan hebben dat niet alleen de Unienationaliteit wordt ingetrokken, maar dat dit mogelijk ook tot staatloosheid zal leiden. ${ }^{22}$ Wat van belang was, is dat de gewezen Duitser Rottmann door het ontnemen van de Oostenrijkse nationaliteit, zijn Unieburgerschap werd ontnomen en hij zodoende ten opzichte van de Unierechten 'staatloos' werd. Aldus opgevat, geldt dit ook voor bipatride Nederlanders met een tweede nationaliteit van een derde land.

Het aangrijpingspunt voor de bevoegdheid om het Unieburgerschap te ontnemen ligt, zoals door het Hof van Justitie uitgemaakt, bij de loyaliteit van de Unieburger jegens de lidstaat. Bij een fraudegeval en het achterhouden van relevante informatie is sprake van schending van die loyaliteit. Het is de vraag of een Unieburger die strijdt in Syrië voor IS of Al-Nusra deloyaal genoemd kan worden aan zijn of haar land en of, en dat is het belangrijkste, dat iets te maken heeft met de tweede nationaliteit. Immers, de lidstaat Nederland heeft ervoor gekozen om artikel 14 lid 4 RWN alleen van toepassing te verklaren op bipatride Nederlanders. Dat moet dus nadrukkelijk in de evenredigheidsbeoordeling worden betrokken, ook al omdat uit het arrest-Rottmann blijkt dat het Hof van Justitie staatloosheid accepteert als er sprake is van deloyaal handelen jegens een lidstaat door diens onderdaan.

21 HvJEU, C-34/09, 8 maart 2011 (Ruiz Zambrano), JV 2011/146 m.nt. P. Boeles. In deze casus nam het HvJEU verblijfsrecht aan ten behoeve van de derdelander moeder van minderjarige EU-burgers levend in het land van herkomst. De potentiële aanspraak en het nuttig effect van het recht van vrij verkeer van goederen en personen zou, aldus het HvJEU, aangetast worden als die kinderen gedwongen waren zich met hun ouder naar buiten de EU te begeven. In casu geldt dat aldus ook voor de betrokkenen die hun potentiële aanspraken gefnuikt zien worden door de intrekking van het Unieburgerschap.

22 Overigens staat het Europees Verdrag inzake Nationaliteit in artikel 7, bedrog bij verwerving als enige rechtsgrond toe die kan worden ingezet ondanks staatloosheid, vergelijk artikel 7 lid 1 onder b jo. 7 lid 2 EVN. 
Wederom lijkt het erop, net als hierboven juridisch dogmatisch is aangetoond ten aanzien van het staatlozenverdrag, dat de hoogste Unierechter middels het begrip loyaliteit aan de lidstaat veel mogelijk is voor de lidstaten als het gaat om ontneming van het Unieburgerschap. Tegelijk ligt het niet voor de hand, gelet op de Unierechtelijke 'blindheid' voor een tweede nationaliteit zoals ontwikkeld in het arrest-Michelletti, dat een lidstaat ermee zal kunnen wegkomen bipatriden anders te behandelen dan monopatride Unieburgers. Immers dan zal de lidstaat moeten aantonen dat bipatride unieburgers intrinsiek meer geneigd zullen zijn tot het plegen van deloyale handelingen zoals het opnemen van de wapenen in het strijdgebied ten faveure van organisaties als Al-Nusra en IS.

\section{Conclusies}

Het zal duidelijk zijn na het voorafgaande dat een tweederangs (Unie)burgerschap niet licht geaccepteerd zal worden door het Hof van Justitie. De ultieme test zal inderdaad zijn dat in de rechtszaal 'discriminatie!' wordt bepleit. Uit de argumenten die hierboven zijn ontwikkeld, blijkt dat in ieder geval in Unierechtelijk perspectief daartoe belangwekkende argumentatie aanwezig is. Hoewel het de vraag is of het toepassingsbereik van de discriminatierichtlijn zo ver rijkt dat ook 14 lid 4 RWN daaronder getoetst zal kunnen worden, kan denkelijk met succes artikel 21 Handvest in het geweer worden gebracht vanwege een ruimer discriminatieverbod. Mogelijk zal de rechter zich gedwongen zien dan ook naar de uitwerking van het discriminatieverbod in het arrest-Chez te kijken. Dat een rechter zich gedwongen zal weten artikel 21 Handvest toe te passen, volgt uit de verplichte evenredigheidstoets volgend uit het arrest-Rottmann. Die evenredigheidsbeoordeling dwingt de lidstaat Nederland dan tot beantwoording van de vraag of bijvoorbeeld Marokkaanse Nederlanders (want die groep Nederlanders heeft vrijwel altijd een dubbele nationaliteit) vanwege hun tweede nationaliteit als minder loyale Nederlanders moet worden beschouwd. Immers alleen dan lijkt het afnemen van het Nederlanderschap zoals vormgegeven in 14 lid 4 RWN ook in Unierechtelijke zin gerechtvaardigd. Het is deze vraag die in de politiek angstvallig wordt en is gemeden. De kans is aanwezig dat de lidstaat Nederland deze vraag in de rechtszaal voor de Unierechter niet langer uit de weg zal kunnen gaan en de burger die vertrouwend op diens rechtsgevoel 'discriminatie!' roept gelijk zal moeten geven. 